\title{
los álcalis y el azufre en el polvo inyectado en el horno de cemento
}

\author{
alkalls and sulphur in a dust injection klln
}

T. PALVIO

("Pit and Quarcy», pág. 84, jalio de 1959.)

Se han publicado cierto número de artículos sobre el comportamiento de los álcalis en los hornos de cemento, y la Portland Cement Association ha hecho un notable trabajo sobre este tema.

El balance de álcalis puede determinarse fácilmente en cada horno, analizando los materiales crudos, el polvo producido y el producto acabado. No obstante, se conoce muy poco lo que octurre dentro del horno.

En St. Lawrence Company, en el proceso de vía húmeda, los hornos van provistos de ocho orificios de toma de muestra, en las zonas de preparación y de cocción. Estos orificios pueden abrirse durante la marcha del horno retirando una especie de casquetes que hacen cierre. El material fluye por el horno y pueden recogerse las muestras en unas cubetas. Se toma una muestra representativa y se mide inmediatamente la temperatura.

La colocación de los orificios y cadenas puede verse en el dibujo adjunto, en el cual también se dan unos datos analíticos concernientes a la humedad, temperatura, cal libre, álcalis y azufre. La humedad se determinó a $110^{\circ} \mathrm{C}$, la cal libre por medio del método del etileno glicol-metil alcohol, los álcalis por medio del espectrofotómetro Beckman $\mathrm{DU}$, el azufre total gravimétricamente en forma de $\mathrm{BaSO}_{4}$ y el azufre de sulfuros con una solución standard valorada en retroceso con $\mathrm{Na}_{2} \mathrm{~S}_{2} \mathrm{O}_{3}$. Los resultados se obtuvieron, excepto para la determinación de la humedad y de la cal libre, tomando como punto de partida muestras libres de perdida, es decir, partiendo del clínker. Para los cálculos, la pérdida al fuego ha sido determinada calentando a $1050^{\circ} \mathrm{C}$ durante media hora. Como puede verse en el dibujo, del orificio núm. 1 no se ha sacado muestra; esto es debido a que la experiencia demuestra que el crudo, a esta altura, está demasiado hứmedo todavía para sacar de él muestra.

Los resultados que también pueden apreciarse en el dibujo, muestran que la mezcla de crudo está completamente seca al final de las cadenas (orificio 4). Esto indica que la parte posterior de las cadenas produce polvo. St. Lawrence Company emplea el principio de inyección de polvo desarrollado por Mooser.

El polvo recogido se inyecta dentro de la zona de cocción a través de la llama, resultando así un aumento en la producción y una mejora en la economía del calor.

La cantidad total de polvo producido puede calcularse analizando el $\mathrm{K}_{2} \mathrm{O}$ en el 
crudo, polvo recuperado y muestras sacadas del orificio número 2 , punto en el que no se produce más polvo debido al elevado contenido de humedad. Los resultados de $\mathrm{K}_{2} \mathrm{O}$, obtenidos partiendo de materiales secos, son los siguientes:

$\begin{array}{lllllllllllll}\text { Crudio } & \ldots & \ldots & \ldots & \ldots & \ldots & \ldots & \ldots & \ldots & \ldots & 0,82 & \% & K_{2} \mathrm{O}\end{array}$

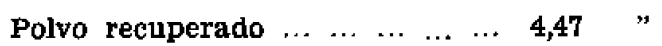

Muestra sacada del orlflcio núm. 2. 1,68 "

Si $x=\%$ de polvo en el orificio número 2, tenemos:

$$
\begin{gathered}
0,82(100-x)=4,47 \times X=1,68 \times 100 \\
y X=23,5 \% \text { (aproximadamante) }
\end{gathered}
$$

No obstante, como las cadenas húmedas retienen una considerable cantidad de polvo, la carga circulante de polvo se estima de un 4 a un $8 \%$ del crudo alimentado seco.

La cantidad de polvo en el orificio número 2 puede calcularse a partir de los resultados obtenidos para el total de $\mathbf{S O}_{3}$, el cual puede determinarse exactamente.

La curva de temperatura indica la eflciente transmisión de calor que tiene lugar en las cadenas secas. La sección de cadenas hace posible conseguir temperaturas relativamente bajas a la salida del horno $\left(450^{\circ} \mathrm{F}\right)$. El intercambio de calor mejora en la zona más estrecha del horno, o sea, en la zona de calcinación, donde la velocidad de los gases es elevada. Sin embargo, la velocidad en la elevación de temperatura es superior en las cadenas secas.

Los materiales erudos en Clarkson son bajos en contenido de azufre, pero el combustible empleado como combustible contiene cerca de un $3 \%$. La curva de azufresulfuro indica una oxidación continua y bastante uniforme de los sulfuros dentro del intervalo ensayado. Fl polvo que vuelye al horno contiene aproximadamente $0,4 \%$ de azufre, pero no está presente en el clinker. Aparentemente, los sulfuros procedentes del combustible arrastrados, a través del horno, con el polvo inyectado se depositan en toda su longitud y parte escapa al sistema de colección de polvo.
Aproximadamente la mitad del total de los sulfuros es soluble en agua.

La parte más interesante de los resultados que se indican en el dibujo es la similitud de formas en las curvas del $\mathrm{K}_{2} \mathrm{O}$ y $\mathrm{Na}_{2} \mathrm{O}$; incluso la curva del $\mathrm{K}_{2} \mathrm{O}$, que presenta un mínimo más acusado, sugiere que una gran proporción de polvo del horno queda retenido en las cadenas húmedas. En la parte más seca de las cadenas la concentración en álcalis es reducida, probablemente porque estas partículas son más pequeñas y se encuentran a mayor altura.

Teóricamente, debiera resultar una reducción de álcalis, si el polvo más fino se separase en el sistema precipitador, o si se instalase una sección de cadenas secas mayor y más densa.

Después de la sección de las cadenas, el contenido de alcalis aumenta, lo que indíca una velocidad de deposición de polvo superior a la de arrastre.

En el clínker, la mayoría de los álcalis aparecen en forma de sulfatos sódico-potásico. Los sulfatos son más difíciles de volatilizar si los álcalis están presentes en exceso en los sulfatos. La fase sulfato puede contener $\mathrm{K}_{2} \mathrm{O}$ y $\mathrm{Na}_{2} \mathrm{O}$ en la proporción molecular de hasta $3 / 1$. El resto de los álcalis se considera que forman $\mathrm{KC}_{28} \mathrm{~S}_{12}$ y $\mathbf{N a C} \mathbf{A}_{3}$. Es de esperar que el polvo inyectado a través de la llama volatilice mejor los álcalis al ser expuesto a una temperatura más elevada, aparte de que se mueva a través de la zona de cocción en forma de clínker.

Como ya sabemos, el potasio volatiliza más rápidamente en los hornos de cemento que el sodio. Esto es lo que ocurre en Clarkson, donde se observaron las siguientes relaciones en peso de $\mathrm{K}_{2} \mathrm{O} y$ $\mathrm{Na}_{2} \mathrm{O}$ :

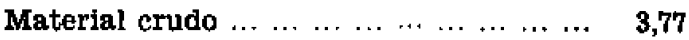

$\begin{array}{llllllllllll}\text { Clinker } & \ldots & \ldots & \ldots & \ldots & \ldots & \ldots & \ldots & \ldots & \ldots & \ldots & \ldots\end{array}$

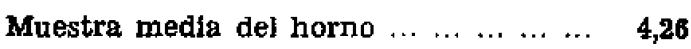

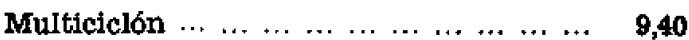




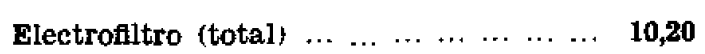

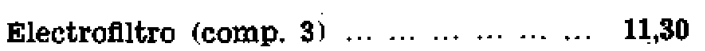

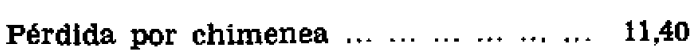

La marcha del horno descrito anteriormente ha sido Hevada en condiciones normales.

Los datos de la operación son los siguientes:

Tiempo del ensayo: 29 septfembre 1958, dos horas.

Agua en la pasta: $\mathbf{3 3 , 8} \%$

Residuo sobre tamiz de $74 \mu$ de apertura: $18,1 \%$.

Producción: 1.110 t/día.

Temperatura de los gases antes de las cadenas: $760^{\circ} \mathrm{C}$.

Oxigeno en los gases de chlmenea: $2,7 \%$.

Dimensiones del horno: $122,5 \mathrm{~m} \times 4,00 \mathrm{~m}$, $3,50 \mathrm{~m}, 4,00 \mathrm{~m}$.
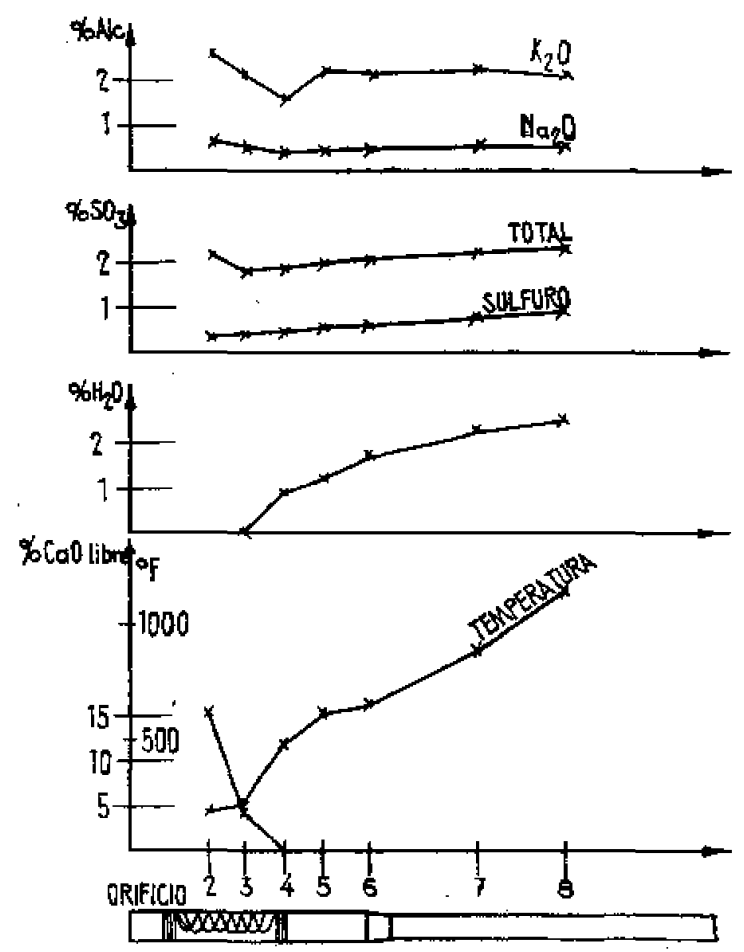

F. S. S. 